\title{
Numerical Evaluation of Reduction of Stress Shielding in Laser Coated Hip Prostheses
}

\author{
Armando Ítalo Sette Antonialli*, Claudemiro Bolfarini \\ Department of Materials Engineering - DEMa, Federal University of São Carlos - UFSCar, \\ Rod. Washington Luís (SP-310), Km 235, CEP 13565-905, São Carlos, SP, Brazil
}

Received: February 17, 2011; Revised: June 14, 2011

\begin{abstract}
The increasing use of titanium alloys as biomaterials can be attributed, among other factors, to their low Young modulus compared to other alloys with similar mechanical strength. However, Ti-6Al-4V alloy, the alloy most widely used in implants, has a stiffness of about $110 \mathrm{GPa}$, which is much higher than the typical stiffness of $20 \mathrm{GPa}$ of human bone. In the specific case of hip arthroplasty, this difference in stiffness reduces the load imposed on the femur through the stress shielding phenomenon, which, in the medium term, usually results in the loss of bone density. One way to reduce this phenomenon is by using TiNbTaZr (TNTZ) alloys, which have a stiffness of about $47 \mathrm{GPa}$. This work uses numerical simulation to evaluate the effectiveness of TNTZ laser coated on a Ti-6Al-4V hip prosthesis in reducing stress shielding. The results show that this may improve the performance of the prosthesis, extending its service life.
\end{abstract}

Keywords: biomaterials, hip prosthesis, titanium alloys, stress shielding

\section{Introduction}

For centuries, efforts have focused on the development of components to repair or replace damaged parts of human tissues effectively. Catheters, stents, plates, pins, lenses, prostheses and numerous other implanted devices have enabled the survival and restored the functionality of biological systems, improving the quality of life of patients suffering from a variety of disorders and disabilities ${ }^{1}$.

Among many surgical procedures involving prosthesis implantation, hip arthroplasty stands out due to the prevalence of femoral neck fracture and other diseases affecting this region of the body. From a mechanical standpoint, moreover, the hip is known to be ideal for arthroplasty, given the simplicity of the coxofemoral articulation compared to that of the knee or ankle, for example, which depend on several ligaments and muscles to maintain their stability ${ }^{2}$.

For these reasons, total hip arthroplasty is being widely employed in the treatment of arthrosis, osteonecrosis, spondylitis, osteoarthritis or fracture, among other diseases that impair this joint, with good short term results with respect to pain relief and recovery of function ${ }^{3-5}$. However, several complications linked to this procedure, such as implant migration, aseptic loosening or osteolysis, are still common in the medium and long term ${ }^{6,7}$. This emphasizes the need for revision surgery, especially in today's context of longer life expectancy and with younger patients requiring hip replacement surgery ${ }^{8,9}$.

All these complications result from proximal adaptive bone remodeling, which is widely known as the stress shielding phenomenon. According to Wolff's law, which states that bone in a healthy person will adapt to the loads it is placed under, the femur may undergo loss of bone mineral density in response to an implanted prosthesis because the stresses acting upon it are lower than those that would act upon it were it healthy ${ }^{10}$. Precisely because the stiffness of prosthetic material is invariably higher than that of bone, their strains must be completely equal at the interface to ensure their compatibility.

Thus, a prosthetic implant made of stainless steel is expected to be less successful than a titanium alloy implant, which has a much lower Young's modulus, as will be discussed later. Figure 1 shows contact microradiography images of the cross section of a tibia after in vivo testing of rabbits implanted with prostheses made of two different titanium alloys, TNTZ (Ti-29Nb-13Ta-4,6Zr) and Ti-6Al-4V ELI, and a stainless steel (SUS 316L) prosthesis, recorded 24 weeks after surgical procedure ${ }^{11}$. As the arrows in the images indicate, the tibia implanted with stainless steel showed lamination and cortical bone atrophy, indicating the occurrence of stress shielding.

Although biphasic $\alpha+\beta$ Ti-6Al-4V alloy is the type most commonly used in biomedical applications, its Young's modulus is still much higher than that of cortical bone, so that stress shielding concerns remain. On the other hand, the stiffness of $\beta$ alloys such as TNTZ is almost as low as that of bone, in addition to their high mechanical strength, possible precipitation hardening, and excellent biocompatibility $^{12}$.

The purpose of this work was to verify the effect of a TNTZ alloy coating laser-applied on a Ti-6Al-4V alloy hip prosthesis on the distribution of stresses in the femur, based on a numerical analysis using the finite element method. Several papers about the deposition of hydroxyapatite on prosthetic surfaces have reported successful improvements in biocompatibility ${ }^{13,14}$, but there is no report about the attempted reduction of stress shielding through the deposition of an alloy of lower stiffness. In the case of success, it would be possible to achieve a reasonable improvement over commercially available prostheses without requiring major investments.

\section{Materials and Methods}

Numerical simulations were performed at the Federal University of São Carlos Center for Materials Characterization and Development (CCDM/UFSCar) using Solidworks Simulation ${ }^{\circledR}$ software. The prosthetic model employed in this work had a cervical-diaphyseal angle of $123.5^{\circ}$ and was taken from the CCDM database, while the model of a femur came from a CAT scan ${ }^{15}$.

Four different situations were simulated for purposes of comparison: a healthy femur and a femur after arthroplasty using 
Ti-6Al-4V ELI, TNTZ (Ti-29Nb-13Ta-4,6Zr), or Ti-6Al-4V ELI laser coated with TNTZ titanium alloy. In the latter situation, the applied coating thickness was about $1 \mathrm{~mm}$.

An orthotropic linear elastic model was used for the femur, using Young's modulus values in the mediolateral $\left(\mathrm{E}_{\mathrm{ml}}\right)$, anteroposterior $\left(\mathrm{E}_{\mathrm{ap}}\right)$ and proximodistal $\left(\mathrm{E}_{\mathrm{pd}}\right)$ directions of the cortical bone, and Poisson's ratio and shear modulus between the mediolateral and anteroposterior $\left(v_{\text {mlap }}\right.$ and $\left.G_{\text {mlap }}\right)$, anteroposterior and proximodistal $\left(v_{\text {appd }}\right.$ and $\left.\mathrm{G}_{\text {appd }}\right)$, and proximodistal and mediolateral $\left(v_{\text {pdml }}\right.$ and $\left.G_{p d m l}\right)$ directions, as shown in Table 1.

An isotropic linear elastic model was applied for the titanium alloys, using the values of Young's modulus (E), Poisson's ratio (v) and shear modulus $(\mathrm{G})$ shown in Table 2.

Loading of the femur can be described as a static $3000 \mathrm{~N}$ load distributed over the femoral head, or over the spherical portion of the prosthesis in post-arthroplasty cases. According to Sabatini and Goswami $^{21}$ (Figure 2), displacement and rotation constraints in all three directions are imposed on the surface of the greater trochanter and on the distal end of the femur.

A perfect contact was designed for each interface between bodies, i.e., prosthesis-coating and coating-femur or prosthesis-femur, thus

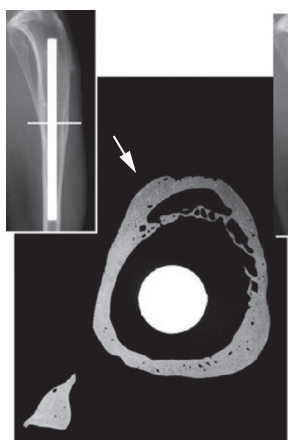

TNTZ

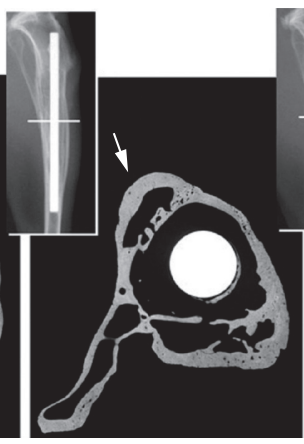

Ti-6Al-4V ELI

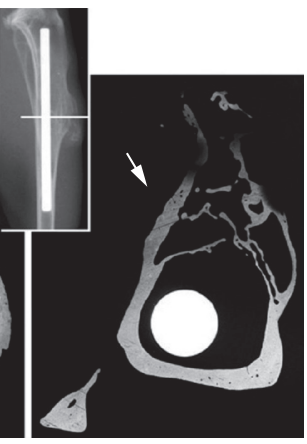

SUS316L
Figure 1. Contact microradiographies of a cross section of tibia after in vivo testing ${ }^{11}$.

Table 1. Mechanical properties of cortical femur ${ }^{16,17}$ apud 18 .

\begin{tabular}{|c|c|c|c|c|c|c|c|c|}
\hline \multicolumn{3}{|c|}{$\mathrm{E}(\mathrm{GPa})$} & \multicolumn{3}{|c|}{$\mathrm{v}$} & \multicolumn{3}{|c|}{$\mathrm{G}(\mathrm{GPa})$} \\
\hline $\mathrm{E}_{\mathrm{ml}}$ & $\mathrm{E}_{\text {ap }}$ & $\mathrm{E}_{\mathrm{pd}}$ & $V_{\text {mlap }}$ & $v_{\text {appd }}$ & $V_{\text {pdml }}$ & $\mathrm{G}_{\text {mlap }}$ & $\mathrm{G}_{\text {appd }}$ & $\mathrm{G}_{\mathrm{pdml}}$ \\
\hline 12.0 & 13.4 & 20.0 & 0.53 & 0.41 & 0.41 & 4.5 & 5.6 & 6.2 \\
\hline
\end{tabular}

Table 2. Mechanical properties of titanium alloys ${ }^{19,20}$.

\begin{tabular}{lcll}
\hline \multicolumn{1}{c}{ Alloy } & $\mathrm{E}(\mathrm{GPa})$ & $\mathrm{v}$ & $\mathrm{G}(\mathrm{GPa})$ \\
\hline Ti-6Al-4V ELI & 113.8 & 0.34 & 42.1 \\
TNTZ & 50 & $0.34^{(*)}$ & $18.7^{(* *)}$ \\
\hline
\end{tabular}

(*)admitting the same Poisson's ratio as Ti-6Al-4V. ${ }^{(* *)}$ shear modulus calculated from $E=2 G(1+v)$.

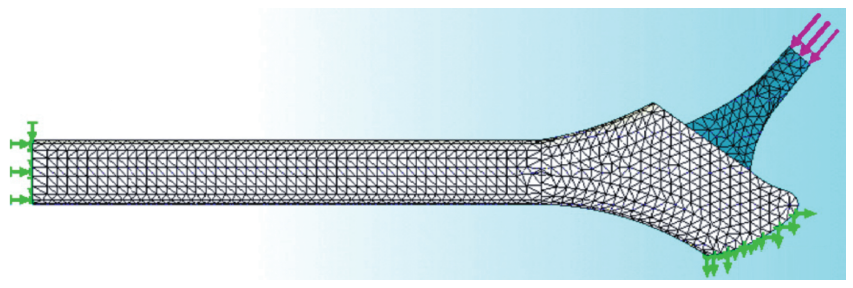

Figure 2. Loading and constraints on femur ${ }^{21}$. preventing sliding at the interface. This assumes that the TNTZ coating on the Ti-6Al-4V prosthesis is completely adherent and that, after arthroplasty, osseointegration between implant and bone is effective.

\section{Results and Discussion}

The stress state of a specific node $(\sigma)$, which comprises the normal stresses in the mediolateral $\left(\sigma_{\mathrm{ml}}\right)$, anteroposterior $\left(\sigma_{\mathrm{ap}}\right)$ and proximodistal $\left(\sigma_{\mathrm{pd}}\right)$ directions and the shear stresses between the mediolateral and anteroposterior $\left(\tau_{\text {mlap }}\right)$, anteroposterior and $\operatorname{proximodistal}\left(\tau_{\text {appd }}\right)$, proximodistal and mediolateral $\left(\tau_{\text {pdml }}\right)$ directions, can be represented by its main stresses $\left(\sigma_{1}, \sigma_{2}\right.$, and $\left.\sigma_{3}\right)$, as shown in Equation $1^{22}$, provided a suitable coordinate system is chosen.

$$
\sigma=\left(\begin{array}{ccc}
\sigma_{\text {ml }} & \tau_{\text {mlap }} & \tau_{p d m l} \\
\tau_{\text {mlap }} & \sigma_{a p} & \tau_{\text {appd }} \\
\tau_{\text {pdml }} & \tau_{\text {appd }} & \sigma_{p d}
\end{array}\right)=\left(\begin{array}{ccc}
\sigma_{1} & 0 & 0 \\
0 & \sigma_{2} & 0 \\
0 & 0 & \sigma_{3}
\end{array}\right)
$$

Von Mises equivalent stress $\left(\sigma_{\mathrm{VM}}\right)$, a scalar stress calculated as a function of the main stresses (Equation $2^{22}$ ), was chosen to describe the stress distribution. This number is proportional to the elastic energy of distortion acting upon each node of the mesh.

$$
\sigma_{V M}=\sqrt{\frac{\left(\sigma_{1}-\sigma_{2}\right)^{2}+\left(\sigma_{2}-\sigma_{3}\right)^{2}+\left(\sigma_{3}-\sigma_{1}\right)^{2}}{2}}
$$

Figure 3 shows the distribution of Von Mises equivalent stresses over a cross section immediately below the small trochanter of the femur in each simulated situation: healthy femur (Figure 3a), and after prosthetic arthroplasty using Ti-6Al-4V ELI (Figure 3b), TNTZ (Figure 3c) and Ti-6Al-4V ELI coated with TNTZ (Figure 3d).

The aforementioned figure clearly shows the presence of stress shielding. In the three post-arthroplasty conditions (Figure 3b, c and d), most of the section of the prostheses (dark red) is subjected to stresses far exceeding the full scale background of 3.00 MPa, and hence, to those imposed on the femur. Therefore, in these situations, the range of stresses below $1.00 \mathrm{MPa}$ (blue) is broader in comparison to that of the healthy femur (Figure 3a).

As expected, the results of arthroplasty with the TNTZ prosthesis (Figure 3c) most closely resembled those of a healthy femur (Figure 3a) due to the low Young's modulus of this alloy. In this situation, the range in which the stresses are lower than 0.25 MPa (dark blue) is totally restricted.

A comparison of the post-arthroplasty results of the Ti-6Al-4V ELI (Figure 3b) prosthesis against those of the Ti-6Al-4V ELI prosthesis coated with TNTZ (Figure 3d) indicated that the stresses in the vicinity of the prosthesis were slightly higher in the latter condition, with a narrowing of the range of stresses below $0.25 \mathrm{MPa}$ (dark blue) and a broadening of the range of stresses between 0.50 and $1.00 \mathrm{MPa}$ (light blue), although no major variations were found in the regions of the cross section containing the highest stresses.

These findings are obviously limited by the relevance of the assumed simplifications. However, the possibility that TNTZ coating on Ti-6Al-4V hip prostheses can improve the latter's performance should be considered a promising one. According to reports in the literature ${ }^{23-25}$, new $\beta$-type TNTZ alloys present mechanical and biochemical properties that render them suitable for application as prosthetic coatings or in the prosthetic stem itself. Of course, accreditation by a competent agency is required and certification may take some time. 

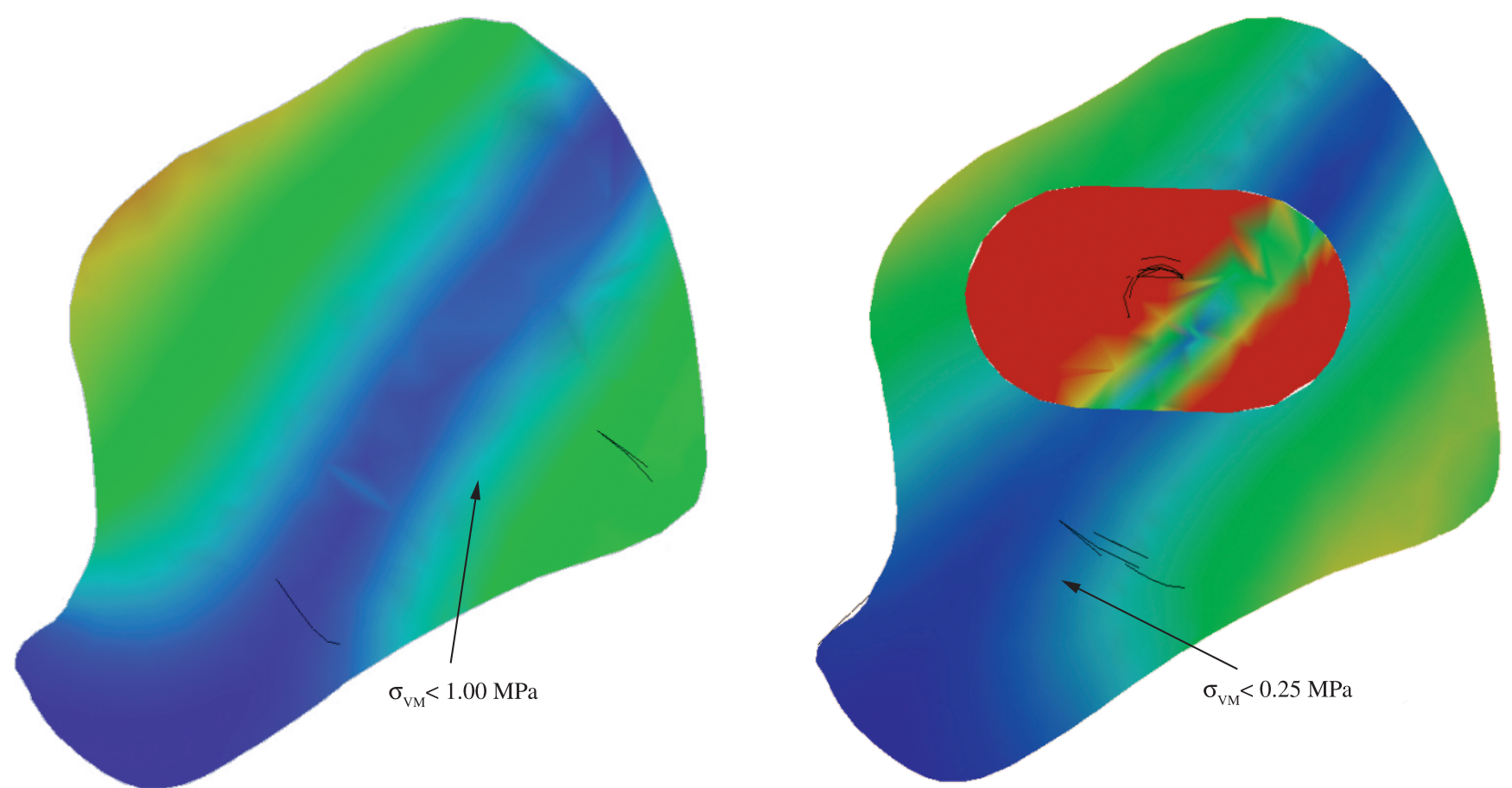

(a)

von Mises $\left(\mathrm{N} / \mathrm{mm}^{2}(\mathrm{MPa})\right)$

(b)

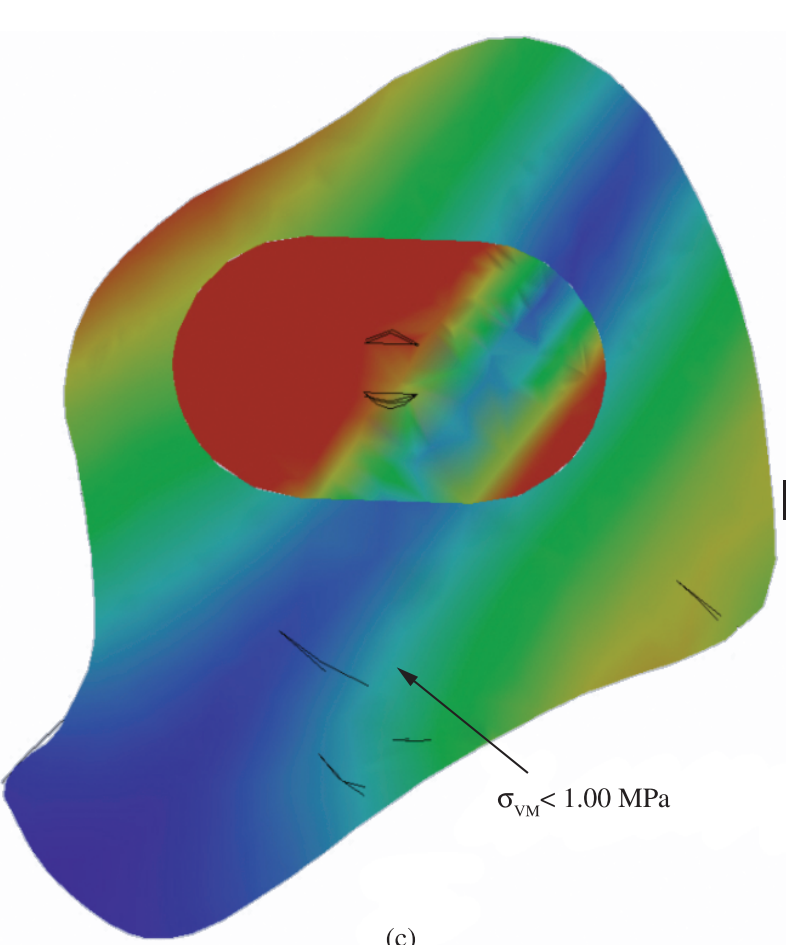

(c)

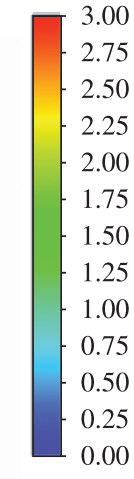

$5 \mathrm{~mm}$

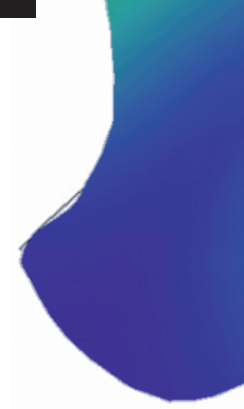

Figure 3. Stress distribution on a) a healthy femur, and post-arthroplasty using b) Ti-6Al-4V ELI, c) TNTZ, and d) Ti-6Al-4V ELI prostheses coated with TNTZ.

\section{Conclusions}

Based on the results of the numerical simulations performed in this work, it can be stated that coating a hip prosthesis of $\alpha+\beta$ titanium alloy, which has a high stiffness, with a thin layer of $\beta$ titanium alloy of lower stiffness, can reduce stress shielding when compared with the uncoated prosthesis. Albeit slight, this reduction may increase the number of years before hip prosthesis revision surgery - a far more invasive procedure than hip arthroplasty - is required

\section{Acknowledgements}

The authors thank the Center for Materials Characterization and Development at the Federal University of São Carlos (CCDM/ UFSCar) for providing the infrastructure for the numerical simulations performed in this study. 


\section{References}

1. Ratner BD, Hoffman AS, Schoen FJ and Lemons JE. Biomaterials science: an introduction to materials in medicine. San Diego: Academic Press; 1996. 484p.

2. Waring TL. Arthroplasty. In: Crenshaw AH, editor. Campbell's operative orthopaedics. Sant Louis: Mosby; 1971. v. 2. cap. 16. p. 1235-1297.

3. Boschin LC and Alencar PGC. Stress shielding: radiographic evaluation after long term follow-up. Revista Brasileira de Ortopedia. 2007; 42(9):290-296.

4. Rabello BT, Cabral FP, Freitas E, Penedo J, Cury MB, Rinaldi ER et al. Artroplastia total do quadril não cimentada em pacientes com artrite reumatoide. Revista Brasileira de Ortopedia. 2008; 43(8):336-342. http://dx.doi.org/10.1590/S0102-36162008000800004

5. Chikude T, Fujiki EN, Honda EK, Ono NK and Milani C. Avaliação da qualidade de vida dos pacientes idosos com fratura do colo do fêmur tratados cirurgicamente pela artroplastia parcial do quadril. Acta Ortopédica Brasileira. 2007; 15(4):197-199. http://dx.doi.org/10.1590/ S1413-78522007000400004

6. Iwana D, Nishii T, Miki H, Sugano N, Sakai T, Ohzono K et al. Proximal bone remodelling differed between two types of titanium long femoral components after cementless revision arthroplasty. International Orthopaedics. 2008; 32(4):431-436. PMid:17464508. PMCid:2532259. http://dx.doi.org/10.1007/s00264-007-0357-2

7. Roos MV, Roos BD, Sampaio CM and Marques Junior PR. Avaliação de método para reconstrução acetabular com uso de enxerto ósseo homólogo e implante cimentado. Revista Brasileira de Ortopedia. 2008; 43(9):367-375. http://dx.doi.org/10.1590/S0102-36162008000900002

8. Devito FS, Aristides RSA, Honda EK and Chueire AG. O uso de enxerto homólogo na revisão de artroplastias do quadril com cimentação do componente acetabular. Acta Ortopédica Brasileira. 2006; 14(5):280-282. http://dx.doi.org/10.1590/S1413-78522006000500011

9. Drumond SN, Drumond FCF, Maranhão BKA and La Cruz LCR. Revisões femorais de artroplastias totais do quadril com afrouxamentos assépticos e fraturas periprotéticas: análise de 49 casos tratados com haste de Wagner. Revista Brasileira de Ortopedia. 2007; 42(7):206-216. http://dx.doi. org/10.1590/S0102-36162007000700005

10. Katti KS. Biomaterials in total joint replacement. Colloids and Surfaces B: Biointerfaces. 2004; 39(3):133-142.

11. Niinomi M. Mechanical biocompatibilities of titanium alloys for biomedical applications. Journal of the Mechanical Behavior of Biomedical Materials. 2008; 1(1):30-42. PMid:19627769. http://dx.doi. org/10.1016/j.jmbbm.2007.07.001

12. Aleixo GT, Button ST and Caram R. Forjamento de hastes de próteses femorais em liga de titânio tipo $\beta$. Anais do XVII Congresso Brasileiro de Engenharia e Ciência dos Materiais; 2007; Sãp Paulo. São Paulo: IPEN, 2007. p. 4311-4322.

13. Kurella A and Dahotre NB. Review paper: Surface Modification for Bioimplants: The Role of Laser Surface Engineering. Journal of Biomaterials Applications. 2005; 20(1):5-50. PMid:15972362. http://dx.doi.org/10.1177/0885328205052974

14. Tian YS, Chen CZ, Li ST and Huo QH. Research progress on laser surface modification of titanium alloys. Applied Surface Science. 2005; 242(1-2):177-184. http://dx.doi.org/10.1016/j.apsusc.2004.08.011

15. Redding Engineering LLC. Large Human Femur: CAD model. Available from: <www.3dcontentcentral.com>. Access in: 05/07/2010.

16. Reilly DT and Burstein AH. The elastic and ultimate properties of compact bone tissue. Journal of Biomechanics. 1975; 8(6):393-396. http://dx.doi. org/10.1016/0021-9290(75)90075-5

17. Ashman RB, Cowin SC, Van Buskirk WC and Rice JC. A continuous wave technique for the measurement of the elastic properties of cortical boné. Journal of Biomechanics. 1984; 17(5):349-361. http://dx.doi. org/10.1016/0021-9290(84)90029-0

18. Black J and Hastings G. Handbook of Biomaterial Properties. London: Chapman \& Hall; 1998.

19. Lampman S. Wrought Titanium and Titanium Alloys. In: Metals Handbook. 10th ed. Materials Park: ASM International; 1990. v. 2 - Properties and Selection: Nonferrous Alloys and Special-Purpose Materials. p. 592-633.

20. Kuroda D, Niinomi M, Morinaga M, Kato Y and Yashiro T. Design and mechanical properties of new $\beta$ type titanium alloys for implant materials. Materials Science and Engineering A. 1998; A243(1-2):244-249. http:// dx.doi.org/10.1016/S0921-5093(97)00808-3

21. Sabatini AL and Goswami T. Hip implants VII: Finite element analysis and optimization of cross-sections. Materials and Design. 2008; 29(7):1438-1446. http://dx.doi.org/10.1016/j.matdes.2007.09.002

22. Beer FP and Johnston Junior ER. Resistência dos materiais. 3th ed. São Paulo: Pearson; 1996. 1255p.

23. Niinomi M. Fatigue performance and cyto-toxicity of low rigidity titanium alloy, Ti-29Nb-13Ta-4.6Zr. Biomaterials. 2003; 24(16):2673-2683. http://dx.doi.org/10.1016/S0142-9612(03)00069-3

24. Niinomi M, Akahori T, Hattori Y, Morikaw K, Kasuga T, Fukui H et al. Super Elastic Functional $\beta$ Titanium Alloy with Low Young's Modulus for Biomedical Applications. Journal of ASTM International. 2005; 2(6):473-488. http://dx.doi.org/10.1520/JAI12818

25. Samuel S, Nag S, Nasrazadani S, Ukirde V, El Bouanani M, Mohandas A et al. Corrosion resistance and in vitro response of laser-deposited Ti-Nb-Zr-Ta alloys for orthopedic implant applications. Journal of Biomedical Materials Research - Part A. 2010; 94(4):1251-1256. 